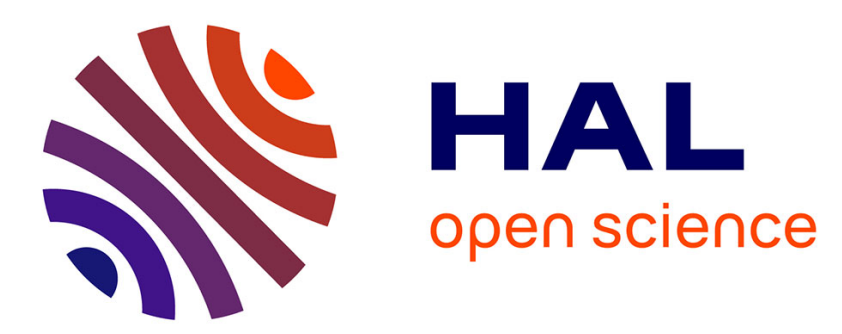

\title{
Exploring the environmental impacts of olive packaging solutions for the European food market
}

\author{
Gwenola Bertoluci, Yann Leroy, Annika Olsson
}

\section{To cite this version:}

Gwenola Bertoluci, Yann Leroy, Annika Olsson. Exploring the environmental impacts of olive packaging solutions for the European food market. Journal of Cleaner Production, 2014, 64, pp.234-243. 10.1016/j.jclepro.2013.09.029 . hal-01159629

\section{HAL Id: hal-01159629 \\ https://hal.science/hal-01159629}

Submitted on 3 Jun 2015

HAL is a multi-disciplinary open access archive for the deposit and dissemination of scientific research documents, whether they are published or not. The documents may come from teaching and research institutions in France or abroad, or from public or private research centers.
L'archive ouverte pluridisciplinaire HAL, est destinée au dépôt et à la diffusion de documents scientifiques de niveau recherche, publiés ou non, émanant des établissements d'enseignement et de recherche français ou étrangers, des laboratoires publics ou privés. 


\title{
Exploring the environmental impacts of olive packaging solutions for the European Food Market
}

\author{
Gwenola Bertoluci $^{a, b}$, Yann Leroy ${ }^{b}$, Annika Olsson ${ }^{c}$ \\ ${ }^{a}$ AgroParisTech, Department SESG \\ ${ }^{\mathbf{b}}$ Ecole Centrale Paris, Laboratoire Genie Industriel, Grande Voie des Vignes, 92290 \\ Chatenay-Malabry, France \\ ${ }^{\mathbf{c}}$ Lund University, Department of Design Sciences
}

\begin{abstract}
Reduction of packaging waste has been a European target for more than 40 years. However, packaging is indispensable for protecting what it carries. In this study, an analysis of the European regulations on packaging and of their resulting effect on recycling performance was performed by means of a literature survey and the national results published in the European Database, Eurostat. Based on these data, two series of five Life Cycle Assessments (corresponding to the national situation of five European countries: France, Germany, Italy, Spain, Sweden) were conducted on three olive packaging solutions: doypacks, glass jars and steel cans. The results highlight the influence of national household waste collection rates and selected technologies for waste treatment (recycling and incineration) on the environmental performance of packaging design. A qualitative analysis of user expectations by means of a questionnaire demonstrates that the environmentally better solution (doypack) was not aligned with user expectations. The loss of food introduced by the better packaging solution is also a reason to question its value. The authors conclude that it is important to increase waste collection rates and recycling in order to actually improve packaging sustainability. They also conclude that eco-design of packaging cannot be considered only in terms of the materials employed: the contribution of the consumers' behavior is also a determinant criterion in the design of food packaging.
\end{abstract}

Keywords

Eco-design; packaging; European Regulation; Life Cycle Assessment 


\section{Introduction}

\subsection{Food packaging Context}

Packaging is an essential way of ensuring that consumers obtain food products that correspond to their food quality and safety expectations. The goal of food supply chains is to deliver products to a large number of consumers in safe conditions. Packaging has a central role in making this possible (Sonneveld, 2000). The basic functions of packaging for the food supply chain are: to contain, protect, conserve, transport, stock, distribute, display the brand image, communicate, fulfill practical needs and provide information on the composition, preparation, and traceability mode of stocking and end-of-life management. Of all these functions, the central ones are protection and conservation to maintain food quality and decrease food waste. Since food and drinks represent 20-30\% of the environmental impact of consumption in the EU (Williams and Wikström, 2011), it is necessary to particularly consider and reduce the environmental impact of these products.

The amount of waste reported varies from country to country. In the United Kingdom, around 11 million tons/year of unconsumed food is thrown away (WRAP, 2010), while 64 million tons/year is wasted in the United States (Jones et al., 2002). Some of this waste is due to the inadequate design of food packaging (Williams et al., 2012), yet other studies show that the environmental impact of packaging is low in comparison to the environmental impact of the food itself (Hanssen, 1998) (INCPEN, 2009). These studies support initiatives to increase the impact of packaging to better protect food and thereby reduce the losses associated with it (Williams and Wikström, 2011). All this supports the necessity to focus research on food packaging and is why it is of particular interest in this study.

The greatest potential for the reduction of food waste in the developed world lays with retailers, food services, and consumers (Lebersorger and Schneider, 2011). In fact in developed countries, cold chain management, efficiency of logistics and (physical and biological) protection of food by packaging have reduced the loss rate in the consumption steps according to the FAO Report (Gustavsson et al., 2011). At the same time in these developed countries, food products and packaging standardization (size, shape, color) have generated a high amount of avoidable waste. In contrast, the absence of these conditions (i.e. transport, processing, packaging and storage in developing countries) leads to high losses of fresh food products such as milk, seafood and vegetables. For this reason, the ability of the package to reduce the environmental impact due to loss of the food itself is the first aspect to take into account when designing it.

Different countries have different systems for handling waste. The actual performance of the end-of-life equipment for packaging waste treatment on the national level varies considerably. This heterogeneity is explained in part by the national preferences of waste treatment type used: recycling or incineration. Another difference is that some countries give priority to the collection and treatment of industrial packaging (secondary and tertiary) over collecting from households. Finally, the performance of industrial units of incineration and recycling are not the same in all European countries.

The approach in the EU Packaging Directive allows Member States to choose the means to achieve the objectives. Consequently, Directive 2006/12/CE (OJEU, 1975b) confers on Member States the responsibility for implementing the collection and treatment of end-of-life waste. Member States are also required to develop policies for waste prevention. Indeed, certain parameters such as population density of waste per square kilometer can positively or negatively influence the impact of a type of organization on waste collection or recycling 
process (Lundie and Peters, 2005) (Eriksson et al., 2005). The only way to resolve the dilemma of comparing different systems is to adopt the Life Cycle Assessment (LCA) (AFNOR, 2006) or other holistic approaches to analyze each situation and identify the best solution in each specific context from a systems perspective.

The differences found in the deployment of the EU Packaging Directive and in the industrial infrastructures that exist in the different Member States, as well as the differences in waste handling and amount of waste in those states, has led to formulating the following research question for this study:

\section{How well do the packaging systems in different European countries perform environmentally?}

The first two recommendations of the Packaging Directive relate to anticipated waste production and re-use of products in the final phase. However, the monitoring of waste packaging collection and recycling rates may not fully reflect the efforts conducted. Other perspectives should be considered in defining the ability of packaging to meet the Directive recommendations. Based on previous work (Abi Akle et al., 2013), the authors hypothesize that an analysis of consumer behaviors and expectations towards packaging is another way to examine packaging performance when it comes to waste aspects. This perception is expressed in our second research question:

\section{How do consumers' preferences and behaviors correspond with regulation-driven environmental design of packaging?}

The purpose, based on the research questions, was to carry out a literature study to compare situations in different EU countries. Then, LCAs were performed on a particular product in three different packaging solutions. This was followed by a consumer questionnaire for the same packaging solutions in order to compare them. The authors show that the deployment of regulations is not sufficient to achieve a universal eco-design in all European countries.

\subsection{A holistic approach to the packaging system}

In addition to the product itself, three levels must be taken into account when designing a packaging system (Jönson, 2000; Saghir, 2004): primary, secondary and tertiary (Fig. 1). The primary packaging, or sales unit, contains the product and displays all the social functions required by B2C relations. The secondary packaging, or distribution unit, ensures that the sales unit is transported safely and in such a way as to facilitate shelf stocking. The tertiary packaging, or loading unit, facilitates loading and transport on pallets. All these levels are interrelated: redesigning one will affect the others. 


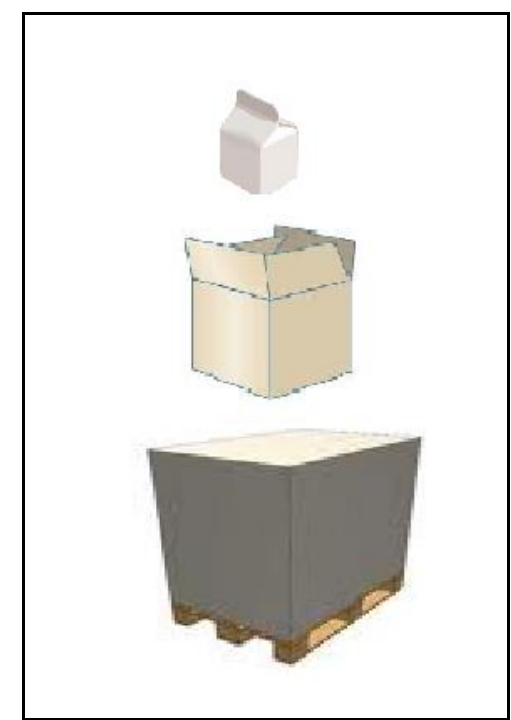

Fig. 1. The three packaging levels

The integrated development of these three levels is essential to enable the optimization of the physical, economic and environmental performances of the whole system. The packaging design team must be able to integrate the technical constraints of transport, distribution and consumer preferences to reduce

- the number of products damaged in transit

- the volume and weight being transported, and

- the handling of the packaging system by different actors throughout the supply chain.

The design of food packaging can be a highly complex exercise because the product and its packaging must satisfy a large number of constraints and expectations. Its usability is also an important factor of interest to end users. Packaging also often plays an essential role in attracting the consumer. Finally, price is known to be a crucial element in the purchasing decision. The promises conveyed by the packaging must truly attract and express the qualities of the product that is to be consumed.

\subsection{European waste management policy}

Originally, environmental regulations on packaging were created through the more general text of the Directive on Waste Management (OJEU, 2006) and the Directive on Hazardous Waste (OJEU, 1975a), both of which were adopted in 1975. The development of regulations that followed centered on emissions resulting from end-of-life treatment systems for packaging (OJEU, 1999, 2000b). The concept of a hierarchy of priorities concerning household waste appeared in 1996, defining European priorities:

- anticipate waste production

- re-use products in the final phase of a life cycle stage

- recycle or compost materials

- recover energy from materials

- dispose of waste in landfills.

The recommended means include integrating end-of-life scenarios in any design of products (as in the WEEE Directive (OJEU, 2003) and in the ELV Directive (OJEU, 2000a)]), applying the principle of "the polluter must pay", and developing systems of waste collection and treatment. This involves: 
- choices in end-of-life product design that enable a technically and economically feasible means of end-of-life extraction and recycling of component materials, or their extraction with a view to exploit a volume of "positive" energy.

- systems of waste collection and treatment to obtain new materials and/or energy.

\subsection{European policy on packaging management}

Directive 2004/12/EC (amending Directive 94/62/EC) (OJEU, 2004) entitled "Packaging and Packaging Waste" concerns packaging commercialized within the European area. The packaging covered by the Directive includes primary (sales units), secondary (distribution units) and tertiary (loading units). This Directive limits the total weight of authorized heavy metals to $100 \mathrm{ppm}$ and established a set of performance criteria that was expected to be reached by 2008: 55 to 60\% of the packaging weight (according to the type of packaging) had to be valorized or incinerated with heat recovery. New recycling targets have been defined for 2015 (see Fig. 2).

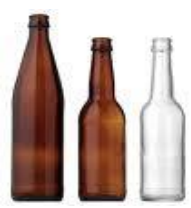

Glass 60\%

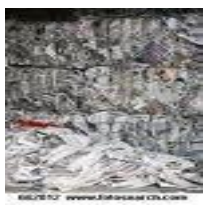

Paper 60\%

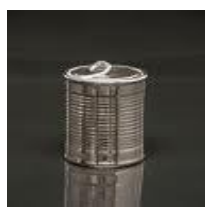

Metal 50\%

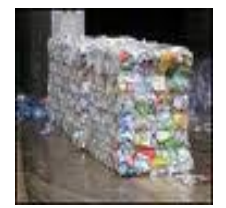

Plastic 50\%

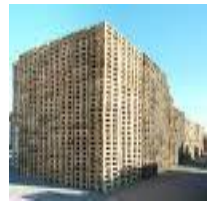

Wood $15 \%$

Fig. 2. Recycling targets for materials contained in domestic packaging waste (values to be reached by 2015 by all European Member States).

\section{Materials and methods}

This study is divided in two parts to answer the two research questions.

The first part compares the industrial performances of packaging waste treatments in five European countries: Germany, Sweden, Spain, Italy and France. These countries were among the first Member States to implement the first Packaging Directive. Therefore, they have most likely developed similar and good practices for the environment based on the Directive.

Three principal types of material for olive packaging were compared: metal, glass and plastic. Comparisons were made of 15 LCAs patterns for the olive packaging alternatives. The LCAs were used to evaluate the performances of the waste treatment units and included the production, distribution and end-of-life of the three olives packaging alternatives in the five countries. In the second step, current household waste collection performances in the respective countries were taken into account. As a result, the environmental impacts of the three packaging alternatives in the five countries could be assessed and compared. In addition, environmental impact must be related to its utility for consumers. This is why, in the second part, a functional analysis (FA) of three olives packaging alternatives was conducted to qualify and quantify this utility. The FA was complemented by a questionnaire sent to users of these products to determine why they chose one of the three packaging solutions. This questionnaire was designed to gain an understanding of consumers' needs and behaviors, but also to see how each product affected the amount of food thrown away.

\subsection{Life Cycle Assessments}

\subsubsection{Software and characterization method}


The LCAs were performed using the Simapro $\odot$ V7 software with the database Ecoinvent V2.0 database (Frischknecht R et al., 2005). All Life Cycle Impact Assessment simulations were conducted with the ReCiPe V1.03 (Goedkoop M et al., 2009) characterization method, Hierarchist $(\mathrm{H})$ version, and European weighting for single score calculation. ReCiPe supplies values of eighteen environmental categories contributed to the calculation of eighteen midpoint impacts categories. The authors selected five of the environmental mechanisms to assess the three packaging alternatives: climate change, human toxicity, particulate matter formation, fossil depletion and ionizing radiation. This was done in order to facilitate interpretations and still be meaningful. The first four impact categories correspond to the main environmental impact categories observed from simulations while the last one, ionizing radiation, is included because of the French specific energy mix with a major contribution of nuclear energy. Most of the data included in the simulations came from the Ecoinvent database, and the performance measurements of the national collecting and recycling value chains were extracted from European statistics (Eurostat, 2009, 2010; Heidorn, 2010).

\subsubsection{System definition}

The three olives packaging alternatives studied were (see Fig. 3):

- A doypack made of multilayered plastic (PE-PET)

- A glass jar with a metal lid and an inner coating of resin

- A steel can made of electrolytic chrome coated steel.

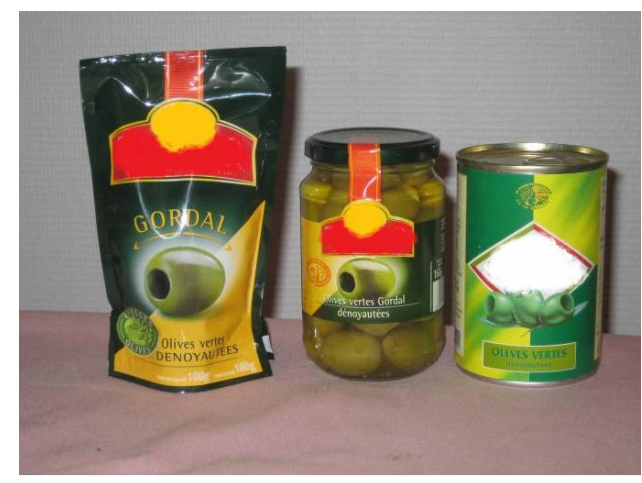

Fig. 3. The three packaging solutions analyzed, from left to right: a doypack, a glass jar, a steel can

The functional unit was defined as "to package one ton of olives for aperitif and cooking usage".

The reference streams to reach such a functional unit were:

- 9345.8 for doypacks

- 6250 for glass jars

- 5555.5 for steel cans.

One should note that the purpose of this study was to address and compare the environmental performance of the packaging only. That is why olives were not directly integrated into the model but their weight was modeled in the logistic phases. Table 1 presents the weights of the brine, the olives and the primary packaging for the three packaging solutions. Weights were obtained through direct measurements during product dissection. Inventories of the material content and weight of packaging are shown in Table 2, modeling parameters and data sources are given in Table 3.

Table 1. Weights of the three packaging solutions in grams 


\begin{tabular}{lcccc}
\hline Packaging & $\begin{array}{c}\text { Total weight } \\
\text { in } \mathbf{g}\end{array}$ & $\begin{array}{c}\text { Weight of } \\
\text { brine } \\
\text { in } \mathbf{~ g}\end{array}$ & $\begin{array}{c}\text { Weight of olives } \\
\text { in } \mathbf{g}\end{array}$ & $\begin{array}{c}\text { Weight of primary } \\
\text { packaging } \\
\text { in } \mathbf{~}\end{array}$ \\
\hline Doypack & 207 & 95 & 107 & 5 \\
\hline Steel can & 461 & 224 & 180 & $\begin{array}{c}\text { Cover 7 } \\
\text { Box 50 }\end{array}$ \\
\hline Glass jar & 530 & 174 & 178 & $\begin{array}{c}\text { Cover } 8 \\
\text { Glass } 170\end{array}$ \\
\hline
\end{tabular}

Table 2. Material content and weight of constituent elements feeding the LCA model

\begin{tabular}{|c|c|c|}
\hline Steel can & Glass jar & Doypack \\
\hline \multicolumn{3}{|c|}{ Classes of primary packaging } \\
\hline Inner surface & Jar & Doypack \\
\hline ECCS (Electrolytic Chrome & Packaging white glass: $170 \mathrm{~g}$ & LDPE (Low Density Polyethylene): \\
\hline Coated Steel) $20 \%$, scrap: $49.4 \mathrm{~g}$ & & $3.75 \mathrm{~g}$ \\
\hline Epoxy resin: $0.6 \mathrm{~g}$ & & $\begin{array}{l}\text { PET (Polyethylene Terephtalate): } \\
1.25 \mathrm{~g}\end{array}$ \\
\hline Cover & Cover & \\
\hline ECCS $20 \%$, scrap: $6.93 \mathrm{~g}$ & ECCS $20 \%$, scrap: $7.889 \mathrm{~g}$ & \\
\hline Epoxy resin: $0.07 \mathrm{~g}$ & Epoxy resin: $0.111 \mathrm{~g}$ & \\
\hline Steel can & Glass jar & \\
\hline \multirow{3}{*}{ Inner surface + cover } & Jar + cover & \\
\hline & & Group box \\
\hline & & $\begin{array}{l}\text { Corrugated board single wall, } 0.650 \\
\left.\mathrm{~g} / \mathrm{m}^{2}-500 * 170 * 110 \mathrm{~mm} \text { ( } 20 \text { units }\right)\end{array}$ \\
\hline \multicolumn{3}{|c|}{ Classes of secondary packaging } \\
\hline Corrugated board double wall & Corrugated board double wall & Corrugated board double wall \\
\hline $\begin{array}{l}0.840 \mathrm{~kg} / \mathrm{m}^{2}-222 * 222 * 216 \mathrm{~mm}- \\
2 \text { layers } * 9 \text { cans (Total: } 18)\end{array}$ & $\begin{array}{l}0.840 \mathrm{~kg} / \mathrm{m}^{2}-300 * 300 * 140 \mathrm{~mm}- \\
1 \text { layer } * 16 \text { jars }\end{array}$ & $\begin{array}{l}0.840 \mathrm{~kg} / \mathrm{m}^{2}-520 * 342 * 110 \mathrm{~mm}(6 \\
\text { units) }\end{array}$ \\
\hline \multicolumn{3}{|c|}{ Classes of tertiary packaging } \\
\hline \multicolumn{3}{|c|}{ Wood based Flat pallet $-0.0117 \mathrm{~m}^{3}$} \\
\hline
\end{tabular}

Table 3. Modeling parameters and data sources employed for the packaging systems description

\begin{tabular}{lll}
\hline Parameters & Values, assumptions & Data sources \\
\hline Materials identification & $\begin{array}{l}\text { Doypack: PE \& PET Composite } \\
\text { Steel can: Epoxy resin coated steel } \\
\text { Glass jar: White packaging glass }\end{array}$ & $\begin{array}{l}\text { Packaging dissection and } \\
\text { characterization } \\
\text { Ecoinvent database }\end{array}$ \\
\hline Weight & See Table 2 & Measurement \\
\hline Material Transportation & - & Included in Ecoinvent modules \\
\hline $\begin{array}{l}\text { Transportation from production to } \\
\text { retailers }\end{array}$ & $200 \mathrm{~km}$ & Assumption \\
\hline Olives losses (not consumed) & See Table 8 & Qualitative questionnaire \\
\hline Country specific collection rate & - & European statistics (Tables 4,5,6) \\
\hline $\begin{array}{l}\text { Country specific material } \\
\text { recycling \& valorization rate }\end{array}$ & - & European statistics (Tables 4,5,6) \\
\hline Energy content & Gross calorific values & \\
& PE & Industrial data \\
& PET & \\
\hline
\end{tabular}




\subsubsection{System boundaries}

The research focused on the packaging itself. The olives - or more precisely their production, transportation, transformation and conditioning processes (dotted lines in Fig. 4) - were excluded from the scope. The model included raw materials preparation, primary, secondary and tertiary packaging production, transportation from production plant to retailers, transportation from retailers to consumers and waste management processes.

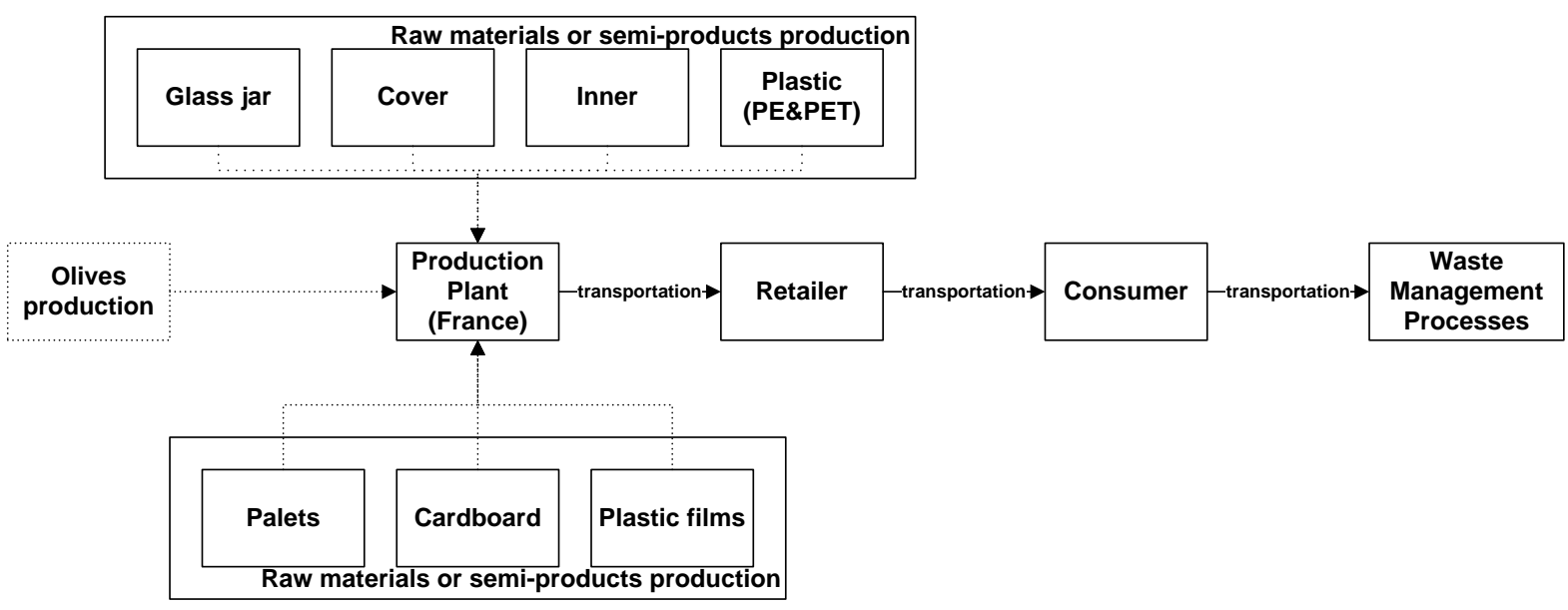

Fig. 4. System boundaries

\subsubsection{Scenarios for packaging end-of-life}

Two sorts of flow collections were modeled in the 15 LCAs: industrial packaging wastes and household packaging wastes. For the industrial flow, composed of the tertiary and secondary packaging, assumptions were the same for all the LCAs: sorting and collection rates are country specific as reported in Table $4 \&$ Table 6 . These flows were then subject to the same recycling and incineration rates as household packaging wastes. 


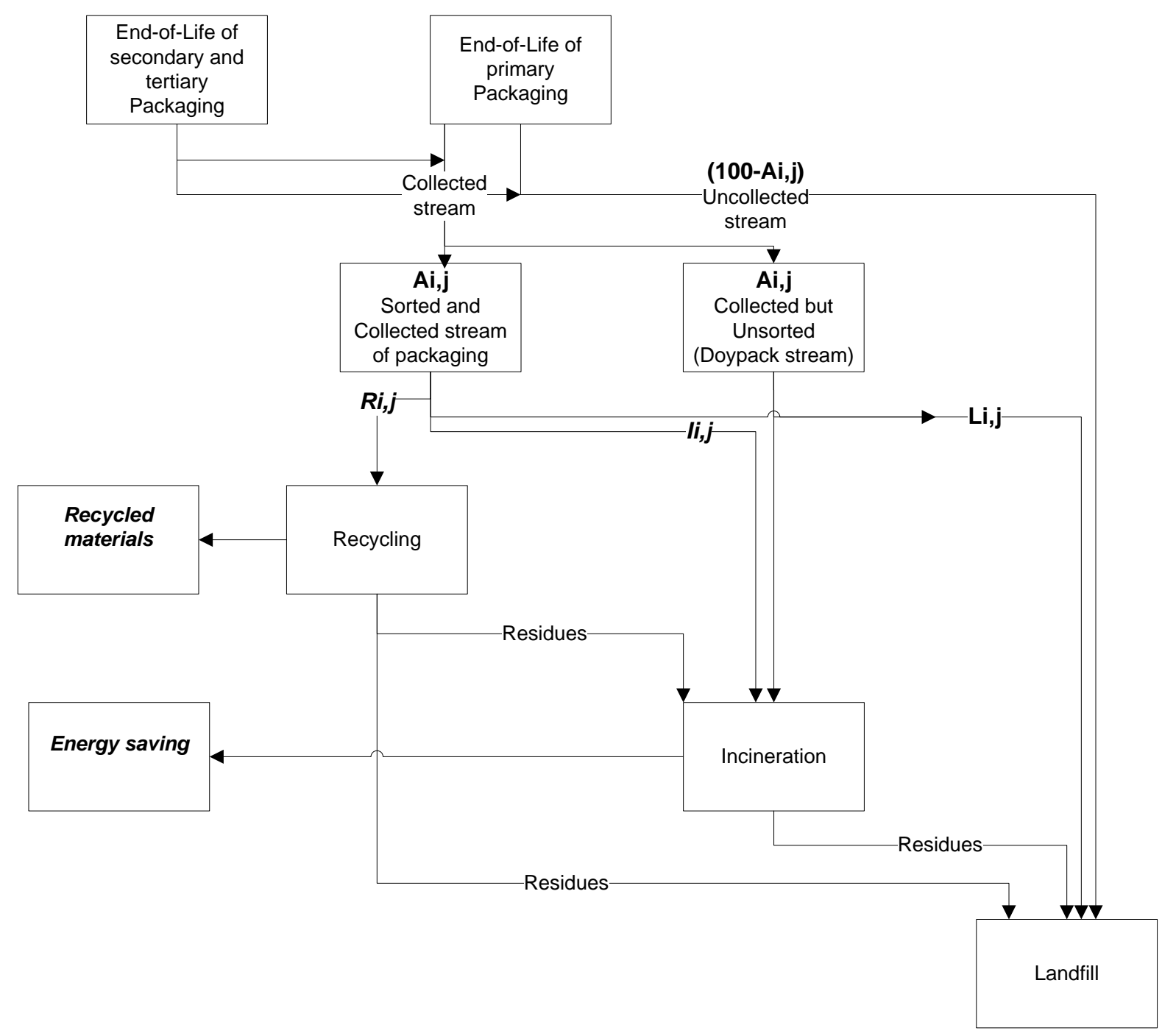

Fig. 5. Modeling of the waste management process employed in the LCAs

\section{NOMENCLATURE}
A Percentage of packaging sorted and collected
$\mathrm{R} \quad$ Percentage of packaging material treated in recycling
I Percentage of packaging material treated in incineration with energy recovery
L Percentage of packaging material put in landfill

Fig. 5 shows the scenarios modeled in the LCAs, using the national rates of collection and recycling for the glass, metal, plastic, cardboard and wood packaging in the five countries and employing them for the three types of packaging. In the five countries, end-of-life scenarios for the glass jar and steel can solutions are in the sorted and collected stream of packaging. The doypack is not sorted in France, Italy, and Spain; its end-of-life is in the domestic waste stream of the country. In Sweden the doypack is sorted at the rate of 50\% and in Germany $100 \%$. In these two countries doypacks are then incinerated.

\subsection{Data employed in the LCAs}

\subsubsection{LCAs to monitor the environmental impact of national industrial performances of packaging waste treatments}

In a first step, the LCAs were conducted assuming a similar household waste collection rate, A, of $80 \%$ across the five countries and a recycling rate, $\mathrm{R}$, in respect to the actual proportion between the collection rate and recycling rate of each country (Table 4). This assumption 
allowed us to measure the influence of environmental performance on the waste packaging treatment organizations themselves (i.e. the choice between recycling and incineration conducted in each country). The Ecoinvent's modules used to model the recycling and energy mix in the different national models are specific to each country. For incineration, energy efficiency and assumptions are the same for all countries.

\begin{tabular}{|l|c|c|c|c|c|c|c|c|c|c|c|c|}
\hline & \multicolumn{3}{|c|}{ GLASS } & \multicolumn{3}{c|}{ PLASTIC } & \multicolumn{3}{c|}{ METAL } & \multicolumn{3}{c|}{ CARDBOARD } \\
\hline & $\mathrm{R}$ & $\mathrm{I}$ & $\mathrm{L}$ & $\mathrm{R}$ & $\mathrm{I}$ & $\mathrm{L}$ & $\mathrm{R}$ & $\mathrm{I}$ & $\mathrm{L}$ & $\mathrm{R}$ & $\mathrm{I}$ & $\mathrm{L}$ \\
\hline France & 80.00 & 0.00 & 20.00 & 34.43 & 45.56 & 20.00 & 79.16 & 0.00 & 20.00 & 71.50 & 8.30 & 20.00 \\
\hline Germany & 80.00 & 0.00 & 20.00 & 38.44 & 40.02 & 20.00 & 79.01 & 0.00 & 20.00 & 74.70 & 6.65 & 20.00 \\
\hline Italy & 80.00 & 0.00 & 20.00 & 40.23 & 39.78 & 20.00 & 79.27 & 0.00 & 20.00 & 72.75 & 7.21 & 20.00 \\
\hline Spain & 80.00 & 0.00 & 20.00 & 48.56 & 31.44 & 20.00 & 80.00 & -9.06 & 20.00 & 74.74 & 5.26 & 20.00 \\
\hline Sweden & 80.00 & 0.00 & 20.00 & 71.75 & 7.63 & 20.00 & 80.00 & 0.00 & 20.00 & 80.00 & 0.00 & 20.00 \\
\hline
\end{tabular}

Table 4. Summary of collecting, recycling and incinerating packaging wastes in France, Germany, Italy, Spain, Sweden in \%. Excerpts from (Eurostat, 2009), (Eurostat, 2010) based on the rate collection assumption of $80 \%$ for all the packaging materials. $\mathrm{R} / \mathrm{I} / \mathrm{L}$ variables stand for percentages of packaging material treated in, respectively Recycling/Incineration/Landfill.

For the unsorted doypack (France, Spain, Italy) or partially sorted (Sweden) the streams were treated with unsorted municipal waste streams with the values indicated in Table 5.

\begin{tabular}{l|rr} 
& \multicolumn{3}{|c}{} \\
& \multicolumn{3}{|c}{ Landfill (\%) } & Incineration (\%) \\
\hline France (FR) & $52.94 \%$ & $47.06 \%$ \\
Germany (DE) & $5.77 \%$ & $94.23 \%$ \\
Italy (IT) & $80.00 \%$ & $20.00 \%$ \\
Spain (SP) & $86.36 \%$ & $13.64 \%$ \\
Sweden (SE) & $2.78 \%$ & $97.22 \%$ \\
\hline
\end{tabular}

Table 5. Assumptions of distribution of unsorted waste streams based on (Eurostat, 2010) values from 2008

\subsubsection{LCAs to monitor the environmental impact of national collecting and recycling packaging performances}

In this step, the previous data are corrected with the real collecting and recycling values of the five countries. All detailed data are showed in the Table 6.

\begin{tabular}{|l|c|c|c|c|c|c|c|c|c|c|c|c|c|c|c|c|}
\hline & \multicolumn{4}{|c|}{ GLASS } & \multicolumn{4}{c|}{ PLASTIC } & \multicolumn{4}{c|}{ METAL } & \multicolumn{3}{c|}{ CARDBOARD } \\
\hline & $\mathrm{A}$ & $\mathrm{R}$ & $\mathrm{I}$ & $\mathrm{L}$ & $\mathrm{A}$ & $\mathrm{R}$ & $\mathrm{I}$ & $\mathrm{L}$ & $\mathrm{A}$ & $\mathrm{R}$ & $\mathrm{I}$ & $\mathrm{L}$ & $\mathrm{A}$ & $\mathrm{R}$ & $\mathrm{I}$ & $\mathrm{L}$ \\
\hline France & 68.12 & 68.12 & - & 31.88 & 58.12 & 25.01 & 33.10 & 41.89 & 65.02 & 64.34 & - & 35.66 & 95.48 & 85.33 & 9.91 & 4.76 \\
\hline Germany & 82.52 & 82.52 & - & 17.48 & 96.78 & 46.50 & 48.41 & 5.09 & 92.80 & 91.65 & - & 8.35 & 95.86 & 89.51 & 7.97 & 2.52 \\
\hline Italy & 65.96 & 65.96 & - & 34.04 & 66.63 & 33.51 & 33.13 & 33.36 & 75.27 & 74.58 & - & 25.42 & 88.44 & 80.43 & 7.97 & 11.6 \\
\hline Spain & 56.52 & 56.52 & - & 43.48 & 43.74 & 26.55 & 17.19 & 56.26 & 70.63 & 70.63 & -8 & 37.37 & 82.09 & 76.69 & 5.40 & 17.91 \\
\hline Sweden & 90.41 & 90.41 & - & 9.59 & 41.51 & 37.23 & 3.96 & 58.81 & 77.74 & 77.74 & - & 22.26 & 74.18 & 74.18 & & 25.82 \\
\hline
\end{tabular}

Table 6. Actual collection rate per material and per country in \%, based on(Eurostat, 2010), (Eurostat, 2009)

\subsection{Integration of consumer needs and behaviors in packaging friendly design}

Eco-design covers more than just the reduction of the environmental impact associated with materials. The objective of eco-design is to maximize the utility of a solution while minimizing its environmental impact. The authors used the functional analysis methodology to establish the main expected functions of an olive packaging (see (Pahl and Beitz, 1984)for the notion of function in design engineering practice and a recent open discussion on Functional Descriptions in Engineering in (Pieter et al., Summer 2013). The results shown in Fig. 10 are a synthesis of the functional analysis conducted by four groups of three university students each. Based on this synthesis, the students evaluated the contribution of the three olive packaging solutions. The ability of the solutions to satisfy each function was assessed on 
a 10-point Likert scale with 1 being the least satisfying and 10 being the most. These values were then added and a global value for each solution was defined.

As a complement, consumer behaviors were qualified through a questionnaire. This semiopen questionnaire was developed and sent to French contacts (11 students and 36 urban, employed people) on the Internet. It asked them:

- If they usually purchased any of the three forms of packaging.

- Their motivations for purchasing or not purchasing each product.

- Their appreciation of each product. (Did they like it or not and why?)

- The proportions of olives thrown in the trash in each case.

The results were a qualitative measurement because the number of respondents was only 47 . Nonetheless, the questionnaire results serve as a complement to the functional analysis.

\section{Results}

\subsection{LCA Results}

\subsubsection{LCA assuming 80\% collection rate (LCA 80)}

The results presented in Fig. 6 (expressed in single scores) suggest that the solution that had the greatest environmental impact was the glass jar, whatever country is considered. The better performance of the doypack in the German case was due to the energy recovery achieved by the $100 \%$ incineration scenario. The results of the other countries are quite similar despite the variability in how waste streams were shared between recycling and incineration. The major variation was found in the German preference for doypack incineration.

The differences between the environmental profiles of the doypack in Fig. 7 are principally explained by the nature of the energy mix used in the countries. Consequently, it is in the doypack solution that one can observe a more distinctive variation. It must be emphasized that Germany incinerates all doypacks. This scenario avoids the pollution that results from the wide use of coal for energy present in the German energy mix (as shown by the climate change avoided by Germany in Fig. 7). Sweden and France are different because a large part of the energy mix for both comes from nuclear energy. 


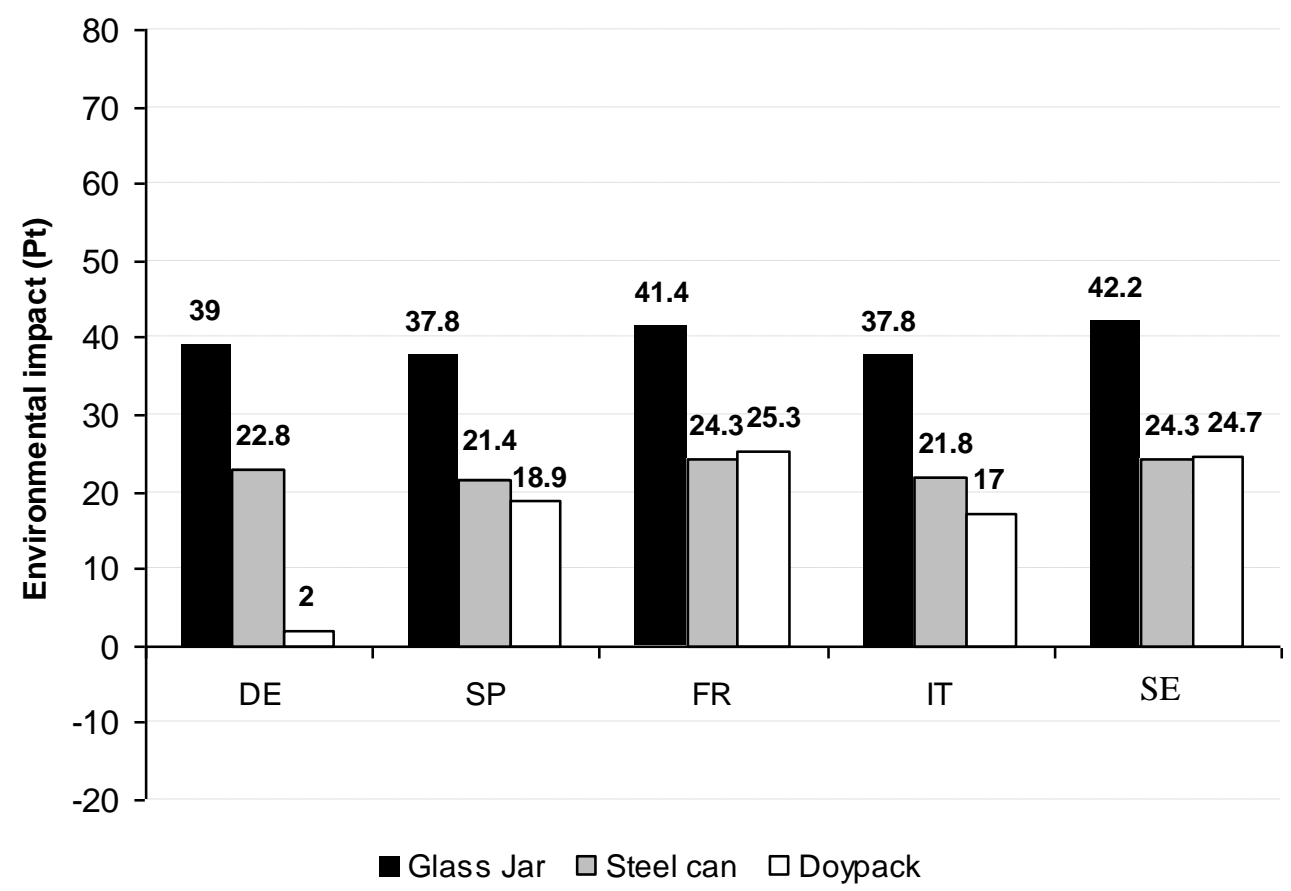

Fig. 6. LCAs of three types of packaging according to country where they were treated and valorized. Environmental impact is expressed in point. The representation aggregates impact categories into a single score using their respective weighting factors and allows comparison between the impacts categories traditionally expressed in different units.

\section{German situation}

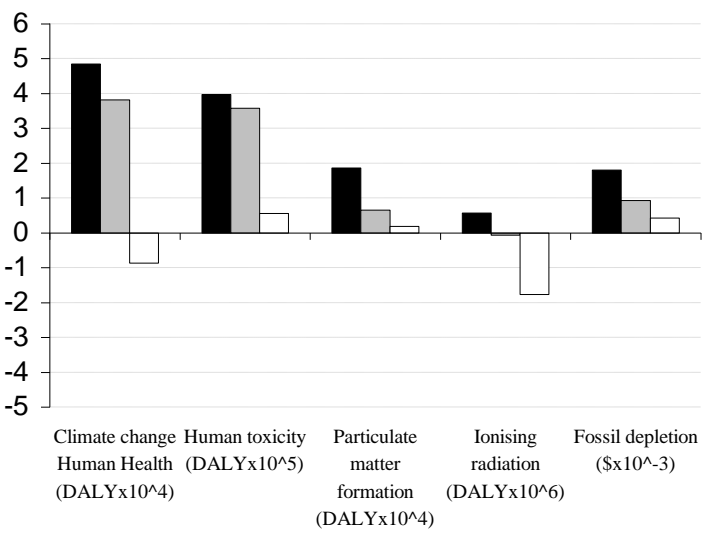

- Glass jar DE $\square$ Steel can DE $\square$ Doypack DE
Spanish situation

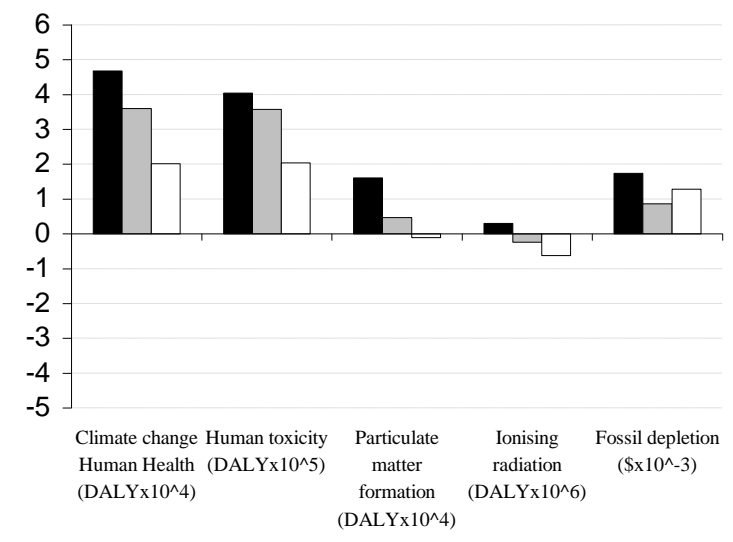

- Glass jar SP $\square$ Steel can SP $\square$ Doypack SP 

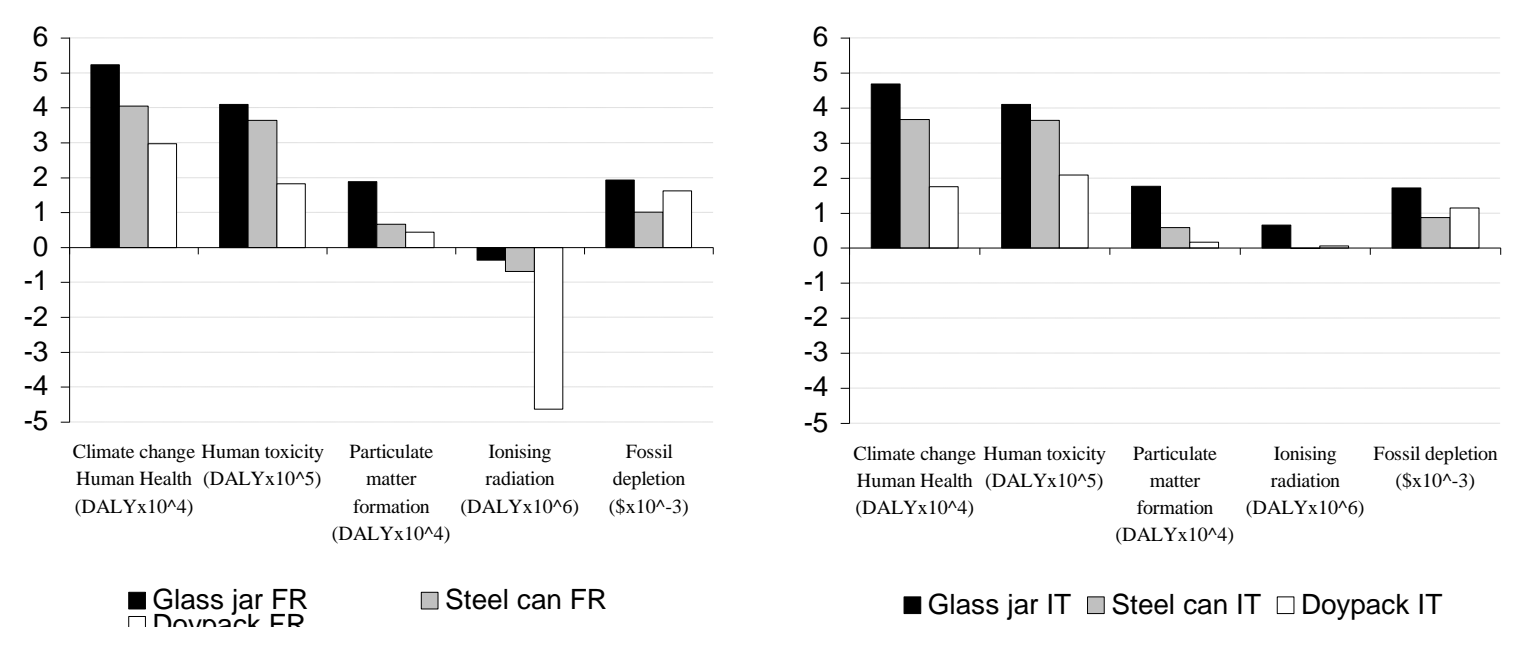

Swedish situation

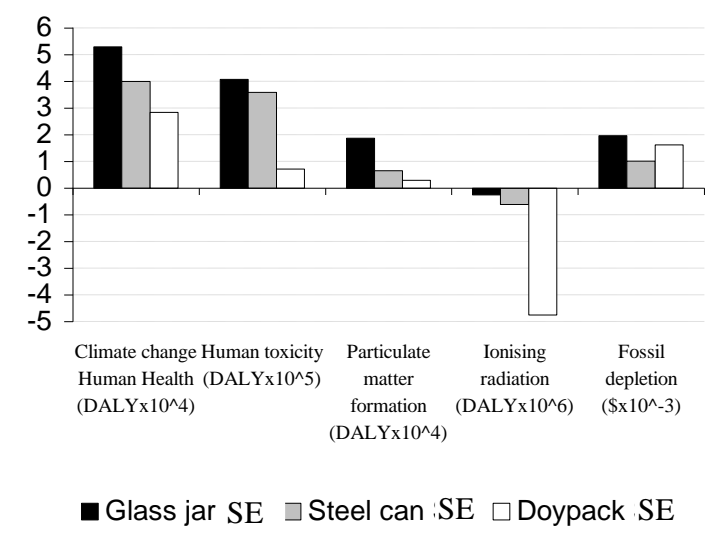

Fig. 7. Country specific LCAs for the three packaging solutions (units are reported in the horizontal axis for each impact category)

Comparing specific environmental profiles, the following conclusions can be drawn. The glass jar appears to be the worst solution in all countries and impact categories considered. The doypack is the best solution considering climate change, human toxicity, particulate matter formation, and ionizing radiation. Specific conclusions can also be drawn regarding ionizing radiation. Indeed, profiles for France, Germany and Sweden strongly argue in favor of the doypack. This can be explained by both countries' specific energy mix and energy saving. In addition, when observing fossil depletion, there was a slight reverse ranking between the doypack and the steel can for France and Sweden because of the mixed energy production in these countries and the couple material-treatment processes. Indeed, when the steel can benefits from the existence of a recycling value chain, the doypack does not. 


\subsubsection{LCA assuming real collection and recycling rates (LCA RR)}

Results from LCAs are presented in Fig. 8 and are expressed as single scores.

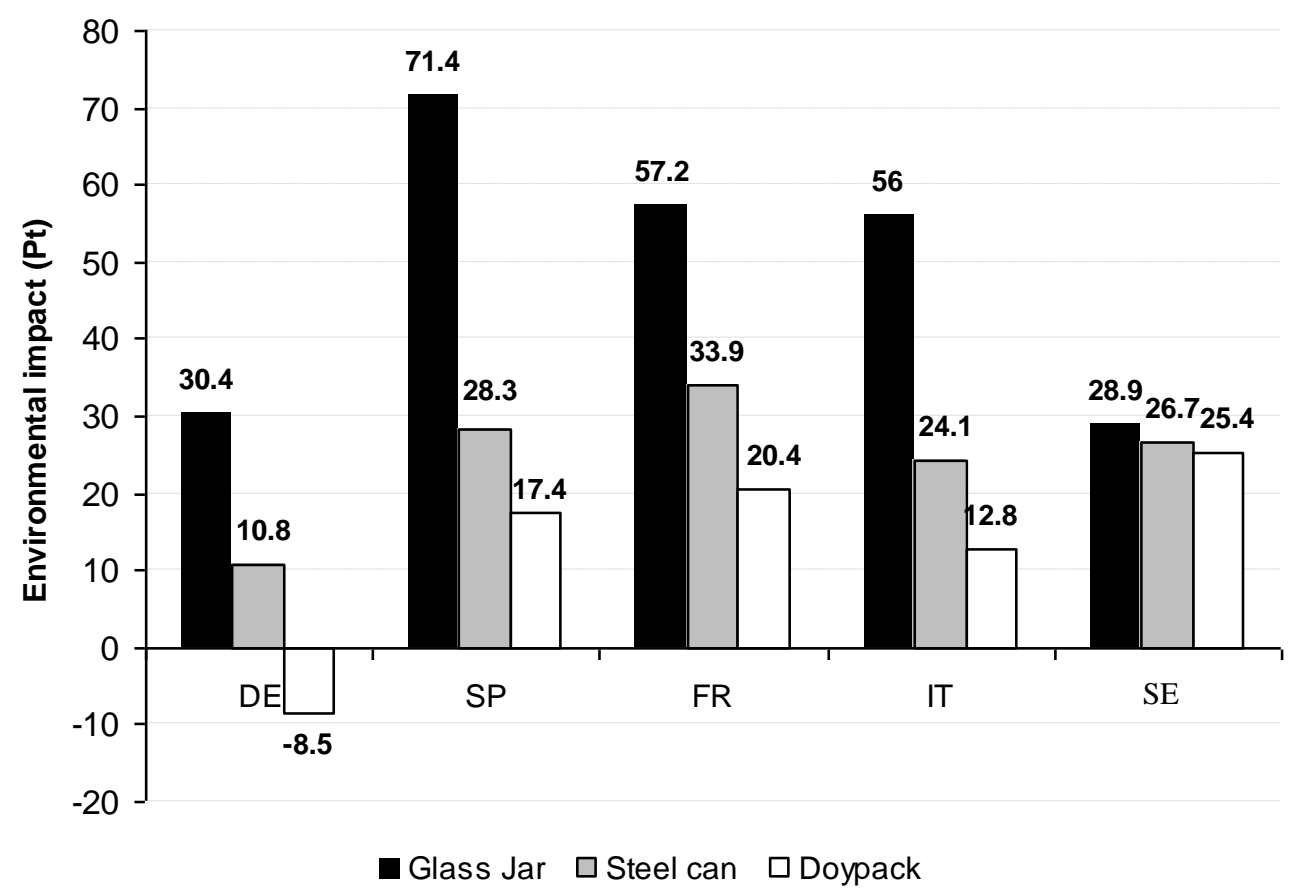

Fig. 8. LCAs of the three packaging solutions, current situation

The results presented in Fig. 8, with actual collection and recycling rates, show that the glass jar solution is still the worst with a higher environmental impact for most countries. The doypack is defined as the best environmental alternative for most countries and its impact decreases in comparison to the previous simulation (with a collection rate of $80 \%$ for all the packaging material). This result is not due to the doypack itself (the doypacks in France, Spain and Italy are unsorted their environmental impact is constant regardless of the rate of plastic packaging collection rate) but to its secondary cardboard packaging. In the second round of calculations, rates of collection and recycling of the cardboard were higher than those used in the first round for France, Spain and Italy. On the contrary, these rates decreased in Sweden, which caused an increase of the doypack environmental impact. These results also show the gain brought about by recycling (vs. incineration) in the case of cardboard. This finding demonstrates the importance of evaluating not only the environmental impact of the primary packaging but that of the complete packaging system. Contrary to other countries, there is no preferred solution for Sweden. 
German situation

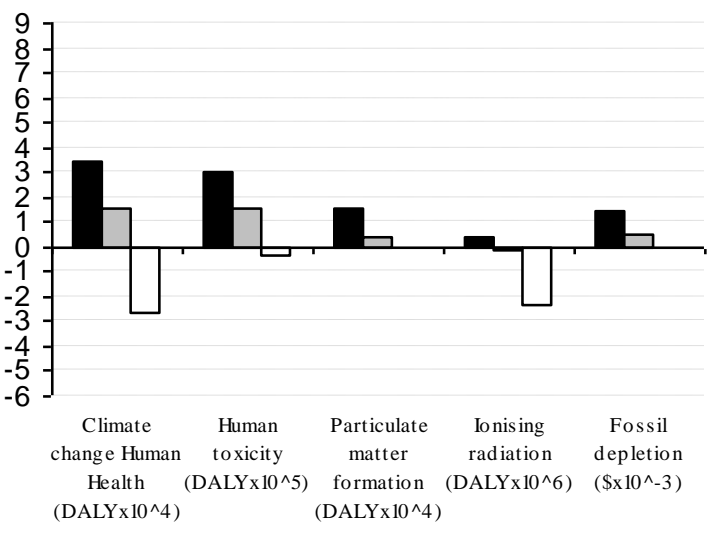

- Glass jar DE $\square$ Steel can DE $\square$ Doypack DE

French situation

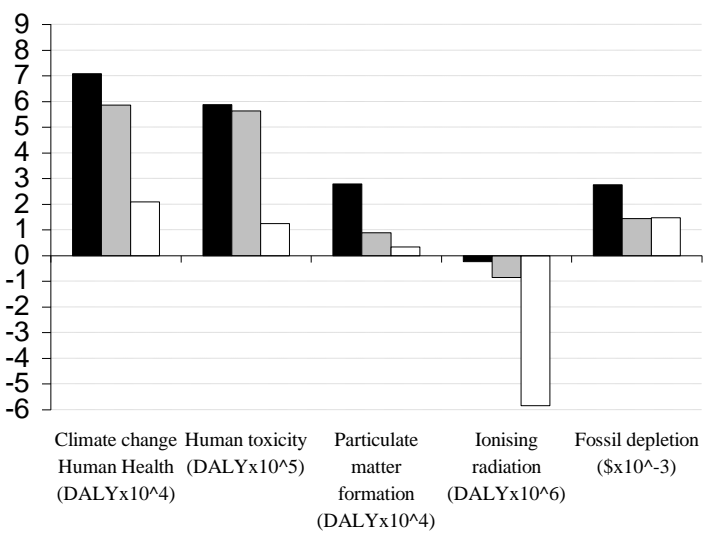

- Glass jar FR $\square$ Steel can FR $\square$ Doypack FR
Spanish situation

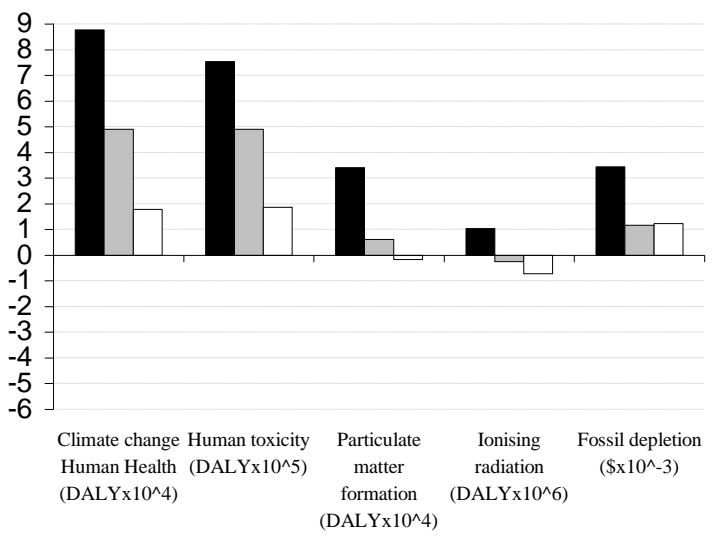

口 Glass jar SP $\square$ Steel can SP $\square$ Doypack SP

Italian situation

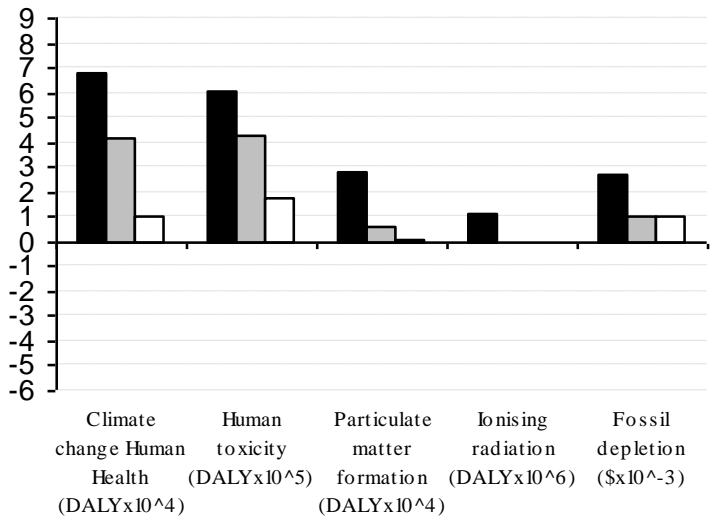

- Glass jar IT $\square$ Steel can IT $\square$ Doypack IT

\section{Swedish situation}

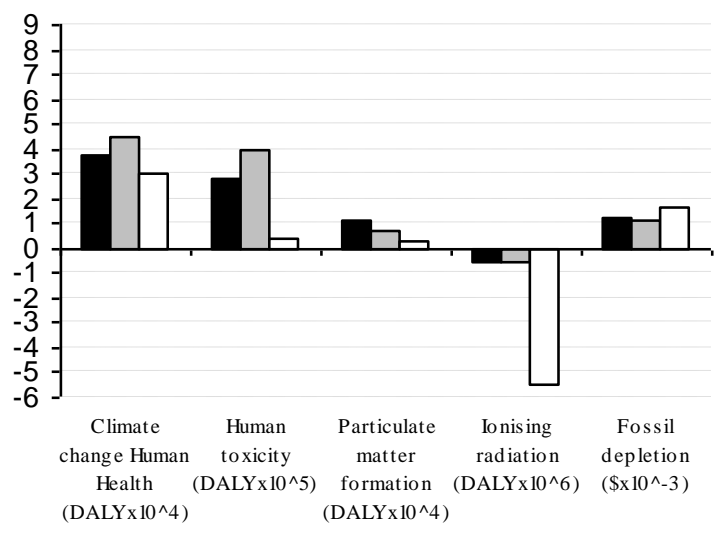

- Glass jar SE $\square$ Steel can SE $\square$ Doypack SE 
Fig. 9. Results of LCAs expressed in characterization values for the three packaging solutions (units are reported in the horizontal axis for each impact category)

From the observation of the five environmental profiles (Fig. 9), it can be concluded that the global performance of packaging is the same for all countries. Indeed, the glass jar solution has the greatest impact, followed by the steel can solution. The doypack is the least impacting solution for the considered impacts. So it is possible, under the actual collecting, recycling and incineration performance of the five countries, to define a unique solution that minimizes environmental impacts in the five countries.

\subsection{Consumer behaviors and preferences results}

Consumer behavior changes depending on the perceived service of the product

(Abi Akle et al., 2013). To analyze the actual service the ideal olive packing would provide, we used a functional analysis.

\subsubsection{Functional analysis of olive packaging}

Fig. 10 shows the elements with which the packaging interacts. The functions that the product must fulfill were then listed as principal functions (PF) and constraints functions (CF). The PFs and CFs were then assessed on a 10-point Likert scale as to how each packaging fulfilled each function (see Table 7).

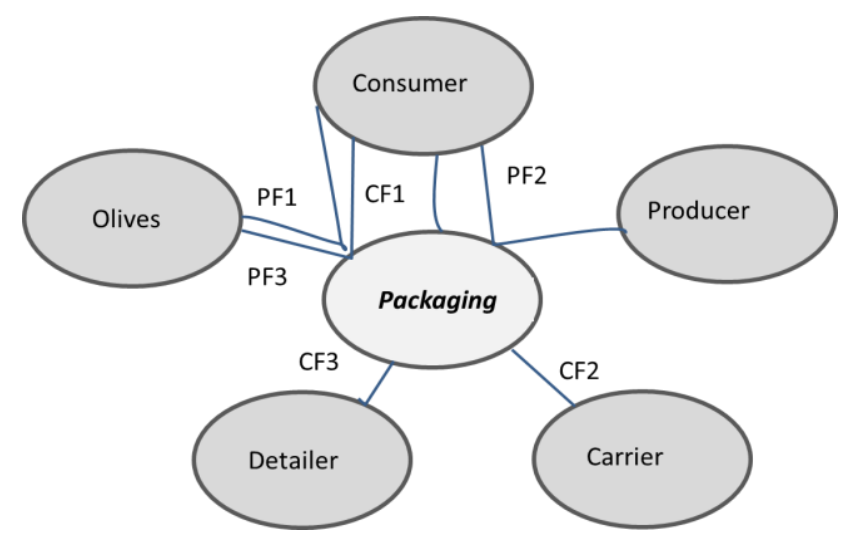

Fig. 10: Functional analysis of olive packaging with six important functions (PF: Principal Function, CF: Constraint Function)

Functions associated with this sort of product are defined as follows:

PF1: storage of olives

PF2: protection of the olives

PF3: information about the product and the brand

CF1: easily opened by the consumer

CF2: able to be transported

$\mathrm{CF} 3$ : facilitating presentation and sale 


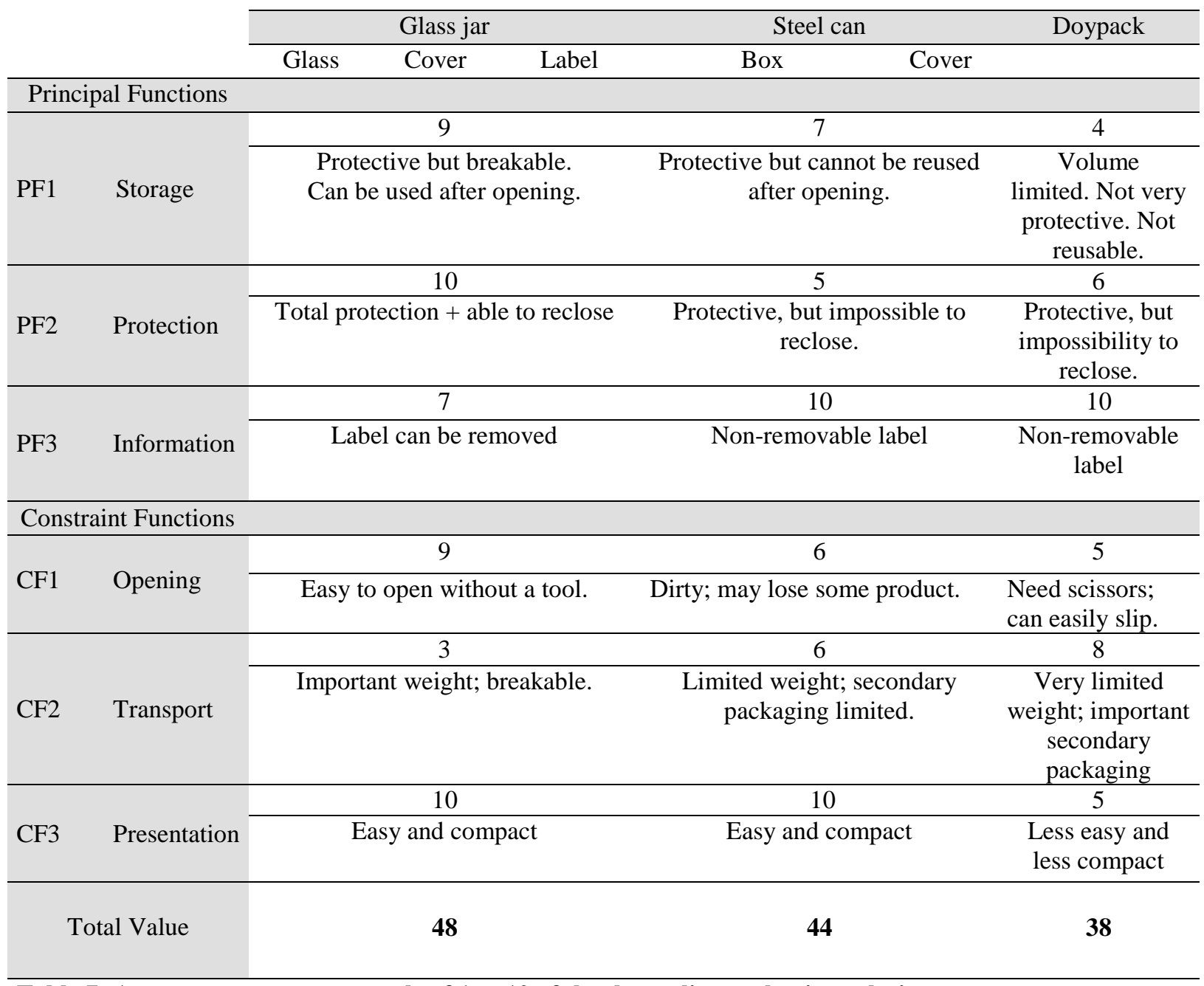

Table 7: Assessment scores on a scale of 1 to 10 of the three olive packaging solutions

The glass packaging appears to offer a better range of services to consumers than its competitors. The next section presents the second aspect analyzed: the consumers' preferences associated with the three packaging solutions.

\subsubsection{Qualitative questionnaire}

This questionnaire results highlight the preference of the consumers for the glass jar (Table 8). Analysis of the responses to the closed-ended questions revealed that this preference is due to the convenience of the glass package that can be reused to store the products once opened. It facilitates the extraction of the olives and brine from the package and is associated with quality and security.

\begin{tabular}{cccc}
\hline & $\begin{array}{c}\text { Percentage of } \\
\text { buyers who } \\
\text { purchase this } \\
\text { package }\end{array}$ & $\begin{array}{l}\text { Percentage } \\
\text { of buyers } \\
\text { who throw } \\
\text { away olives }\end{array}$ & $\begin{array}{c}\text { Percentage of olives } \\
\text { thrown away }\end{array}$ \\
\hline Doypack & $52.18 \%$ & $12.5 \%$ & Approx. 10\% \\
\hline
\end{tabular}




\begin{tabular}{llll} 
Glass jar & $69.96 \%$ & $0 \%$ & - \\
\hline Steel can & $32.6 \%$ & $0 \%$
\end{tabular}

Table 8: Assessment of the three olives packaging solutions from the questionnaire

The questionnaire results strengthen the evidence provided by the functional analysis: the services the glass jar provides are those that best meet consumers' expectations. Even though the doypack is environmentally better than the glass jar in the LCA, this advantage is cancelled out when one takes into account the olives that are thrown away with this solution.

These results call forth the following questions: Do we define sustainable packaging as that which reduces the environmental impact based only on its material composition? Or do we define sustainable packaging as that which has a lower overall environmental impact of the integrated aspects of the packaged product and the packaging by including consumer preferences and behavior?

\section{Discussion and conclusion}

This research deals with factors that affect the environmental quality of food packaging in Europe. In the first step, the authors considered the influence of national choices and performance in terms of collection systems and the treatment of packaging waste on the endof-life environmental impact of packaging. The first outcome shows that despite a common European Directive on food packaging waste, the environmental performance of one type of packaging can greatly differ from one country to another due to different recycling and valorization solutions and because of the country's specific energy mix. The collection systems and current recycling performance are uneven and fluctuating. However, for the case analyzed, the performances of the compared packaging solutions are stable in the five countries; the glass solution is always the worst in an environmental assessment, even though it has a high recycling rate in a country. In parallel, authors show that the interest in glass recycling is highly dependent of the energetic mix employed in the country. In the case of Sweden where the collection and recycling rates are high and the energy mix consists of 50\% of nuclear energy, environmental performances of the glass packaging are better than those of Steel can on several indicators.

The packaging solution with the lowest environmental impact is made of plastic, which is non-renewable and non-recyclable because it is a multilayer material. It is obviously in contradiction with the European Directive (2004/12/EC, amending Directive 94/62/EC, (OJEU, 2004) that recommends limiting the use of non-renewable and non-recyclable materials.

In the context of the case study one can say it is possible to provide the same ecological packaging solution for many European countries. However results highlight the influence of national household waste collection rates and technologies for waste treatment (recycling and incineration) and energetic mix on the environmental performance of packaging design.

But, rather than just complying with environmental impact measures, the design of consumer products has to foremost satisfy the consumer's preferences (Sonneveld, 2000), and packaging has an important role to play in doing so. It must entice, reassure and be convenient to use. A product designed only to reduce the environmental impact may not really penetrate its markets if this aspect is not considered (Fukuyo and Fujita, 2005). 
To develop better packages for Environment, the study shows that it is important to take into account how the packaging affects the use made of food. Finally, services supported by the package, in the utilization phases', have a real influence on the volume of food thrown (according to statements made by consumers in the case study). Consequently, according to (Abi Akle et al., 2013), it appears that assessing the better environmental impact of packaging, without taking into account how it affects useful consumption (i.e. limiting the loss of product content) can be non-productive. Deployment of consequential LCA to account the influence of packaging design on the use phase is a way to integrate these phenomena. In this case and under the condition of really understanding the practices and needs of consumers, it will be possible to create more truly ecological packaging for food.

Consequently it appears essential to use consequential LCA for the eco-design of packaging. Utilization of use phase scenarios of the products would provide a better understanding of the real impact of the use and end of life of a packaging. 


\section{References}

1 Abi Akle, A., Bertoluci, G., Minel, S., 2013. From environmental assessment to usage centered eco-design: taking into account the real impact of container-content system for the liquid laundry detergent, Iced 2013, Seoul.

2 AFNOR, 2006. Management environnemental - Analyse du cycle de vie - Principes et cadre, NF EN ISO 14040. , p. 12.

3 Eriksson, O., M., C.R., Frostell, B., 2005. Municipal solid waste management from a systems perspective. Cleaner Production 13, 241-253.

4 Eurostat, 2009. Packaging Waste for France, Germany, Italy, Spain, Sweden. European Union.

5 Eurostat, 2010. 40\% des déchets minicipaux ont été recyclés ou compostés en 2008. European Union.

6 Frischknecht R, Jungbluth N, Althaus HJ, Doka G, Dones R, Heck T, Hellweg S, Hischier R, Nemecek T, Rebitzer G, M, S., 2005. The ecoinvent Database: Overview and Methodological. Int J Life Cycle Ass 10, 3-9.

7 Fukuyo, K., Fujita, K., 2005. Conflicts between eco-design and usability of refrigerators in: IEEE (Ed.), 4th International Symposium on Environmentally Conscious Design and Inverse Manufacturing - EcoDesign 2005. Union of Ecodesigners, Tokyo, pp. 762-763.

8 Goedkoop M, Heijungs R, Huijbregts MAJ, De Schryver A, Struijs J, Van Zelm R, 2009. ReCiPe 2008: A life cycle impact assessment method which comprises harmonised category indicators at the midpoint and the endpoint level. in: Pre Consultants, C.U.o.L. (Ed.).

Radboud University, RIVM Bilthoven, Netherlands, p. 44.

9 Gustavsson, J., Cederberg, C., Sonesson, U., Van Otterdijk, R., Meybeck, A., 2011.

Global food losses and food wastes. Extent, causes and prevention. , in: FAO (Ed.),

International Congress Save Food! at Interpack2011, FAO, Düsseldorf, Germany, p. 38.

10 Hanssen, O., 1998. Environmental impacts of product systems in a life cycle perspective:

a survey of five product types based on life cycle assessments studies. Journal of Cleaner Production 6, 299-311.

11 INCPEN, 2009. Table for one, the energy cost to feed one person. Industry Council for Packaging and the environment, Berkshire, p. 27.

12 Jones, T., Dahlen, S., Bockhorst, A., Cisco, K., McKee, B., 2002. Household Food Loss

Comparing Tucson, Arizona and Wilmington in: Bureau of Applied Research in

Anthropology, U.o.A. (Ed.). Report to the United States Department of Agriculture,Economic Research Service.

13 Jönson, G., 2000. Packaging technology for logistician, 2nde ed. Lund University, Lund.

14 Lebersorger, S., Schneider, F., 2011. Discussion on the methodology for determining

food waste in household waste composition studies. Waste Management 1924.

15 Lundie, S., Peters, G.M., 2005. Life cycle assessment of food waste management options. Journal of Cleaner Production 13, 275-286.

16 OJEU, 1975a. Hazardous Waste, Directive 91/689/EEC European Parliament and the Council, Brussel.

17 OJEU, 1975b. Waste, Directive 75/442/CEE. European Parliament and the Council, Brussel.

18 OJEU, 1999. Landfill Directive 1999/31/EC. European Parliament and the Council, Brussel.

19 OJEU, 2000a. End-of-life vehicles. European council, Brussel.

20 OJEU, 2000b. Waste Incineration 2000/76/EC. European Parliament and the Council, Brussel. 
21 OJEU, 2003. Waste electrical and electronic equipment (WEEE). Union Européenne, Brussel.

22 OJEU, 2004. Packaging and packaging waste 2004/12/EC. European Parliament and the Council, Brussel.

23 OJEU, 2006. Waste, Directive 2006/12/EC. European Parliament and the Council.

24 Pahl, G., Beitz, W., 1984. Engineering Design The Design Council, Springer, London.

25 Pieter, V., Eckert, C., editors, Summer 2013. Special Issue on "Functional Descriptions in Engineering". AIEDAM.

26 Saghir, M., 2004. A platform for packaging logistic development - a system approach, Design Sciences, Division of Packaging Logistics. Lund University, Lund.

27 Sonneveld, K., 2000. What drives (food) packaging innovation? Packaging Technology and Science 13, 29-35.

28 Williams, H., Wikström, F., 2011. Environmental impact of packaging and food losses in a life cycle perspective: a comparative analysis of five food items. Journal of Cleaner Production 19, 43-48.

29 Williams, H., Wikstrom, F., Otterbring, T., Lofgren, M., Gustafsson, A., 2012. Reasons for household food waste with special attention to packaging. Journal of Cleaner Production, 141-148.

30 WRAP, 2010. Waste arising in the supply chain and drink to households in the UK.

WRAP, Banbury, p. 86. 